\title{
Analisis Faktor-Faktor yang Mempengaruhi Persepsi Jurnalis Televisi terhadap Perkembangan Bank Syariah Di Indonesia
}

\section{Analysis Of Factors Affecting Television Journalist Perception On Islamic Banking Development In Indonesia}

\author{
Rizki Amelia' ${ }^{1}$, Didin Hafidhuddin², Hendri Tanjung ${ }^{3}$ \\ ${ }^{1}$ Mahasiswa Magister Bisnis Syariah Institut Pertanian Bogor, JL. Raya Pajajaran Bogor-Jawa \\ Barat. Email: ramelia85@gmail.com \\ ${ }^{2}$ Ketua Dosen PembimbingMagister Bisnis Syariah Institut Pertanian Bogor. Email: \\ hafidhuddin@yahoo.com \\ ${ }^{3}$ Anggota Dosen PembimbingMagister Bisnis Syariah Institut Pertanian Bogor. Email: \\ hendri.tanjung@gmail.com
}

\begin{abstract}
Indonesia is the largest Moslem population in Southeast Asia (CIA, 2013), but Islamic banking market share in Indonesia is still low (BI,2014). This condition happened because Islamic banking information was not well accepted in the society. Television journalist has important role in spreading this information. The purpose of this study was to analyze perception and factors that build television journalist perception in Islamic banking news making. This study used theory of planned behavior (TPB) and structured equation modeling (SEM) to assess television journalist perception in Indonesia's Islamic banking development. The assessment evaluated intention and ability to explain their intention in subjectivenorm (SN), attitude toward behavior (ATB), and perceived behavior control (PBC). The result showed that SN, ATB, and PBC were positively influence television journalist perception on Islamic banking development in Indonesia. SN and $\mathrm{PBC}$ were positively influence journalist intention to make Islamic banking news.
\end{abstract}

\section{Keywords : Journalist, Perception, Theory of Planned Behavior (TPB), Structural Equation Modeling (SEM)}

\begin{abstract}
Abstrak. Pangsa pasar bank syariah di Indonesia masih tergolong rendah (BI, 2014), padahal Indonesia merupakan Negara berpenduduk muslim terbesar di Asia Tenggara (CIA, 2013). Hal ini terjadi dikarenakan informasi bank syariah belum diterima dengan baik di masyarakat. Jurnalis televisi memiliki andil penting dalam penyebaran informasi ini. Tujuan penelitian ini adalah menganalisis persepsi dan faktor-faktor yang membentuk persepsi jurnalis televisi dalam pembuatan berita mengenai bank syariah. Penelitian ini menggunakan menggunakan theory of planned behavior (TPB) dan structured equation modeling (SEM) untuk melihat persepsi jurnalis televisi terhadap perkembangan bank syariah di Indonesia melalui pengukuran niat dan kemampuan menjelaskan maksud mereka dalam hal subjective norm (SN), attitude toward behavior (ATB), dan perceived behavior control (PBC). Hasil analisa data menunjukkan SN, ATB, dan PBC secara positif mempengaruhi persepsi jurnalis televisi terhadap perkembangan bank syariah di Indonesia. Selain itu, peubah SN dan PBC secara positif mempengaruhi niat jurnalis dalam membuat berita bank syariah.
\end{abstract}

Kata kunci: Jurnalis, Persepsi, Theory of Planned Behavior (TPB), Structural Equation Modeling (SEM)

\section{Pendahuluan}

Masyarakat Indonesia seharusnya telah memiliki rekening dan menggunakan jasa perbankan syariah dengan maksimal, mengingat bank syariah telah hadir di Indonesia sejak tahun 1992, melalui peresmian Bank Muamalat oleh Presiden Soeharto.Indonesia memiliki jumlah masyarakat muslim terbesar di Asia Tenggara, yaitu mencapai 190.113.060 orang. Jumlah dan aset bank juga mengalami peningkatan (Tabel 1). 
Para praktisi perbankan syariah telah melakukan berbagai upaya untuk mengembangkan bank syariah, namun berdasarkan data Bank Syariah per Agustus 2014, pangsa pasar bank syariah hanya mencapai 5,5\% dari total aset perbankan Indonesia. Jumlah rekening perbankan syariah baru mencapai 12 juta rekening atau 9,2 persen dari total rekening perbankan nasional. Bank Indonesia (2014) merilis penyebab rendahnya pangsa pasar bank syariah, diantaranya dipicu oleh tekanan kebijakan moneter pemerintah. Irviana (2008) menyebutkan ada beberapa faktor lainnya, diantaranya kurangnya informasi mengenai bank syariah sehingga masyarakat menganggap belum perlu bank syariah. Salah satu upaya untuk menangggulangi permasalahan tersebut ialah melalui sosialisasi media massa. Hal ini karena media massa punya fungsi menyampaikan informasi kepada masyarakat, yang menyangkut masyarakat dan atau yang dibutuhkan masyarakat.

Tabel 1 Perkembangan perbankan syariah tahun 2009-Oktober 2014

\begin{tabular}{|c|c|c|c|c|c|c|}
\hline Indikator & 2009 & 2010 & 2011 & 2012 & 2013 & 2014 \\
\hline \multicolumn{7}{|l|}{ BUS } \\
\hline a. Jumlah Bank & 6 & 11 & 11 & 11 & 11 & 12 \\
\hline b. Jumlah Kantor & 711 & 1.215 & 1.401 & 1.745 & 1.998 & 2.157 \\
\hline \multicolumn{7}{|l|}{ UUS } \\
\hline a. Jumlah UUS & 25 & 25 & 24 & 24 & 23 & 22 \\
\hline b. Jumlah Kantor & 287 & 262 & 336 & 517 & 590 & 362 \\
\hline \multicolumn{7}{|l|}{ BPRS } \\
\hline a. Jumlah Bank & 138 & 150 & 155 & 158 & 163 & 163 \\
\hline b. Jumlah Kantor & 225 & 286 & 364 & 401 & 402 & 431 \\
\hline Indikator & \multirow{2}{*}{\multicolumn{6}{|c|}{ (dalam jutaan Rupiah) }} \\
\hline Kinerja & & & & & & \\
\hline a. Total Aset & 2189.671 & 2.836 .264 & 3.665 .884 & 4.893 .970 & 6.075 .764 & 6.526 .802 \\
\hline b. Pembiayaan & 1.633 .805 & 2.128 .618 & 2.778 .585 & 3.701 .025 & 4.617 .614 & 5.144 .247 \\
\hline $\begin{array}{l}\text { c. Dana Pihak } \\
\text { Ketiga }\end{array}$ & 1.212 .314 & 1.681 .824 & 2.212 .759 & 3.087 .326 & 3.851 .721 & 4.009 .025 \\
\hline d. Laba Rugi & 67.832 & 85.206 & 101.955 & 130.207 & 160.547 & 116.371 \\
\hline
\end{tabular}

Tak hanya itu, media massa juga punya banyak pengaruh di masyarakat, McGuire (1986) dalam Perse (2001) mencatat beberapa pengaruh media, diantaranya pengaruh iklan terhadap pembelian produk, kampanye politik terhadap pemungutan suara, dan propaganda ideologi. Data Badan Pusat Statistik tahun 2012 menunjukkan jumlah penduduk 10 tahun ke atas selama seminggu yang menonton acara televisi berjumlah 91,5\%. Hal ini membuktikan bahwa penduduk Indonesia, mayoritas menonton televisi daripada membaca surat kabar atau koran (Grafik 1).

Acara berita dan informasi di televisi dapat menjadi wadah untuk meningkatkan pangsa pasar bank syariah. Pemberitaan didukung oleh tim produksi berita, termasuk di dalamnya jurnalis. Selama tahun 2013 terdapat 10.381 program acara yang tayang di 10 televisi swasta terrestrial. Jumlah program berita dan informasi mengenai bank syariah selama tahun 2013 hanya berjumlah sebanyak 5 program, dengan waktu tayang mingguan. Jumlah program dan pemberitaan mengenai perbankan syariah meningkat di saat bulan Ramadan (CKM Metro TV, 2014) 


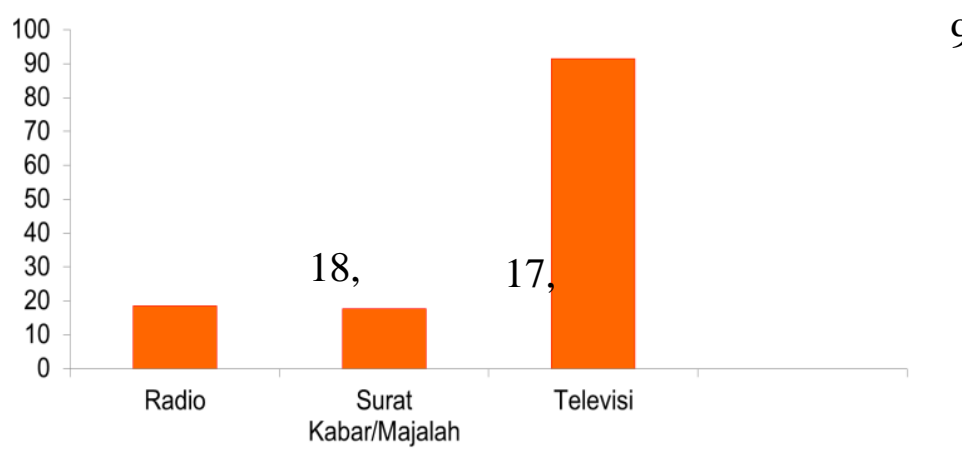

\section{Grafik 1 Jumlah penduduk Indonesia 10 tahun ke atas terhadap media}

Peranan jurnalis telah disampaikan pada beberapa ayat dalam Al Quran, yaitu: 1. QS. Al Hujurat (49) ayat 6, yaitu: "Hai orang-orang yang beriman, jika datang kepadamu orang fasik membawa suatu berita, maka periksalah dengan teliti agar kamu tidak menimpakan suatu musibah kepada suatu kaum tanpa mengetahui keadaannya yang menyebabkan kamu menyesal atas perbuatanmu itu" 2. QS. Al Ashr (103) ayat 3, yaitu: "kecuali orang-orang yang beriman dan mengerjakan amal saleh dan nasehat menasehati supaya mentaati kebenaran dan nasehat menasehati supaya menetapi kesabaran.

Berita berkualitas dilahirkan dari proses pembuatan berita yang sesuai dengan kode etik jurnalis di Indonesia. Persepsi seorang jurnalis juga akan mengantarkan pemirsa pada tujuan yang dimaksudkan oleh pembuat berita. Persepsi dalam Schiffman dan Kanuk (2007) ialah sebagai proses individu memilih, mengorganisasi, dan menginterpretasikan stimuli ke dalam gambaran realita yang bermanfaat dan koheren. Persepsi dapat dideskripsikan sebagai cara seseorang melihat dunia di sekelilingnya. Oleh karena itu perlu dibuat penelitian mengenai faktor-faktor yang mempengaruhi persepsi jurnalis televisi terhadap perkembangan bank syariah di Indonesia.

Persepsi jurnalis televisi telah terbukti mempengaruhi perilaku pemirsa pada PEMILU Presiden dan Wakil Presiden Indonesia pada tahun 2014. Dua televisi berita di Indonesia, yaitu TV One dan Metro TV terbelah. TV One secara eksplisit mendukung pasangan nomor 1 Prabowo Subianto-Hatta Rajasa, sedangkan Metro TV mendukung pasangan nomor 2 Joko Widodo-Jusuf Kalla. Persepsi para jurnalis televisi yang bernaung di kedua televisi tersebut dapat terlihat melalui pemberitaannya. Jelang pemungutan suara berlangsung, jurnalis Metro TV semakin gencar memberitakan Joko Widodo-Jusuf Kalla, yang akhirnya memenangkan PEMILU Presiden periode 2014-2019. Pasangan Joko Widodo-Jusuf Kalla unggul dengan perolehan suara 53,15\% dari suara sah nasional, sedangkan pasangan Prabowo Subianto-Hatta Rajasa mendapat 46,85\% dari suara sah nasional (KPU, 2014). Hal ini membuktikan, persepsi yang dimiliki oleh jurnalis dapat mempengaruhi perilaku masyarakat yang menyaksikan televisi.

Penelitian ini bertujuan untuk menganalisis persepsi dan faktor-faktor yang membentuk persepsi jurnalis televisi dalam pembuatan berita mengenai bank syariah, khususnya dengan menggunakan theory of planned behavior (TPB) oleh Bray (2008) yang mengonstruksikan persepsi kontrol perilaku berdasarkan kombinasi antara persepsi faktor-faktor yang memfasilitasi dan menghambat kekelangsungan perilaku. 


\section{Metode Penelitian}

Penelitian ini mengintegrasikan theory of planned behavior (TPB) dengan variabel laten eksogen/variabel bebas yang digunakan, yaitu sikap terhadap perilaku (attitude toward behavior), norma subjektif (subjective norms), dan persepsi kontrol perilaku (perceived behavioral control) dengan 18 indikator yang diamati. Variabel endogen/variabel terikat yaitu niat (intention). TPB banyak digunakan untuk memprediksikan persepsi perilaku.

\subsection{Model and Hipotesis}

Analisis TPB dengan analisis structured equation modeling banyak digunakan dalam penelitian-penelitian sikap dan kontrol keperilakuan. Menurut Ghozali (2005), Stuctural Equation Modeling (SEM) merupakan suatu teknik analisis statistik multivariate, yang memungkinkan peneliti untuk menguji hubungan antara variabel yang kompleks baik recursive maupun non-recursive untuk memperoleh gambaran menyeluruh mengenai suatu model. Warmanto (2007) menggunakan TPB dan SEM untuk menganalisis hubungan antara sikap, norma subyektif dan kontrol keperilakuan yang dirasakan terhadap perilaku berbagi pengetahuan manajer. Hasilnya menunjukkan model riset sesuai dengan data. Perilaku berbagi pengetahuan manajer dipengaruhi oleh niat, sikap manajer, norma subjektif, dan persepsi kontrol perilaku. Gambar 1 menunjukkan hipotesis yang digunakan pada penelitian ini dengan mengkombinasikan elemen dari TPB.



Gambar 1 Hipotesis Penelitian

Dalam hipotesis, niat digunakan untuk melihat faktor-faktor yang mempengaruhi perilaku. Ajzen (1991), Attitude toward behavior (ATB) menunjukkan tingkat seseorang suka atau tidak suka terhadap evaluasi perilaku di pertanyaan. Subjective norm (SN), menunjukkan tekanan sosial untuk melakukan atau tak melakukan sebuah perilaku. Perceived behavioral control (PBC) didefinisikan sebagai persepsi seseorang dari kesulitan menunjukkan perilaku.

Hipotesis dalam Gambar 1 dapat disimpulkan menjadi sebagai berikut: Hipotesis 1 (H1): Subjective norm (SN) berpengaruh terhadap Intention. Hipotesis 2 (H2): Attitude toward behavior (ATB) berpengaruh terhadap Intention. Hipotesis 3 (H3): Perceived behavioral control (PBC) berpengaruh terhadap Intention.

\subsection{Pengumpulan Data}

Populasi dalam penelitian ini adalah para jurnalis televisi yang berkantor di Jakarta dan telah melewati masa kerja minimal 1 tahun. Jumlah jurnalis televisi di Jakarta yang 
tergabung dalam Asosiasi Jurnalis Indonesia (AJI) pada tahun 2014, yang beragama Islam berjumlah 400 orang, sedangkan yang tergabung dalam Ikatan Jurnalis Televisi Indonesia (IJTI) yang beragama Islam berjumlah 350 orang. Berdasarkan data dari kedua organisasi tersebut, maka populasi jurnalis televisi beragama Islam yang berkantor di Jakarta dan telah melewati masa kerja minimal 1 tahun adalah 750 orang. Sampel adalah bagian dari jumlah dan karakteristik yang dimiliki populasi. Sampel yang diambil dalam penelitian ini berjumlah 100 responden.

Metode pengambilan sampel yang digunakan adalah metode nonprobability sampling, dimana peluang untuk memilih unit contoh tidak diketahui. Penelitian ini menggunakan teknik snowballsampling, yaitu sampel awal diambil dengan metode probability, sedangkan tambahan sampel diperoleh dari referensi sampel awal terpilih (Tanjung dan Abrista 2013).

Penelitian ini menggunakan kuesioner struktural sebagai data primer. Kuesioner berisikan 18 pertanyaan yang berhubungan dengan parameter model hipotesis yang dapat dilihat pada Lampiran 1.. Pengumpulan data dilakukan pada bulan Oktober hingga November 2014 dengan jumlah 100 jurnalis televisi sebagai responden.

\subsection{Pengolahan dan Analisis Data}

Penelitian ini menggunakan analisis SEM berbasis variance, dengan software SmartPLS dan PLS Graph. Covariance based SEM lebih bertujuan memberikan pernyataan tentang hubungan kausalitas atau memberikan deskripsi mekanisme hubungan kausalitas (sebabakibat). Component based atau variance based SEM dengan PLS lebih bertujuan untuk mencari hubungan linier prediktif antar variabel (Ghozali, 2008). Contoh model path PLS disajikan pada Gambar 2.

Pemodelan analisis jalur dalam PLS terdiri dari tiga set hubungan, yaitu:1. Inner model (structural model); menspesifikasikan hubungan antar variabel laten berdasarkan teori.2. Outer model (measurement model); menspesifikasikan hubungan antar variabel laten dengan indikator. 3. Weight Relation; Inner dan Outermodel memberikan spesifikasi yang diikuti dalam estimasi algoritma PLS.Berdasarkan operasionalisasi variabel tersebut, maka model SEM untuk penelitian kali ini bisa dilihat pada Gambar 3. Analisa deskriptif dalam penelitian ini diolah dengan bantuan software SPSS.

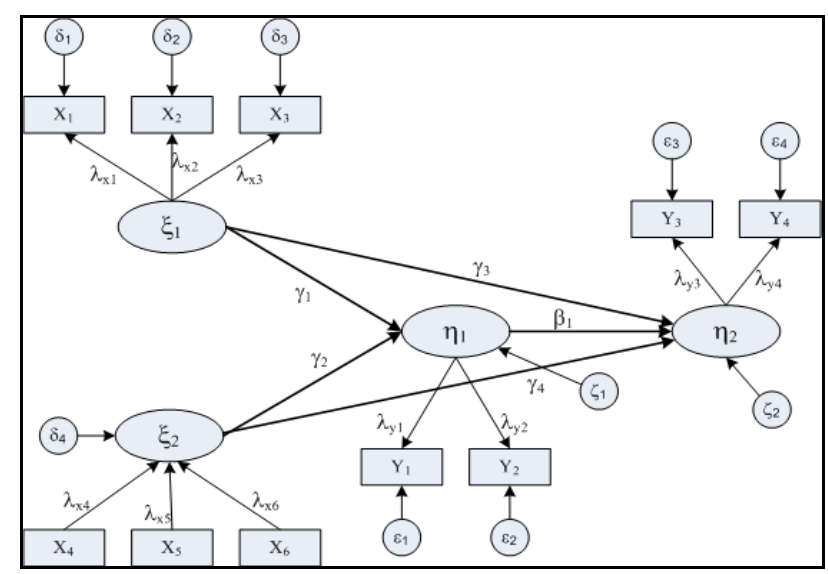

Gambar 2 Contoh model path PLS 


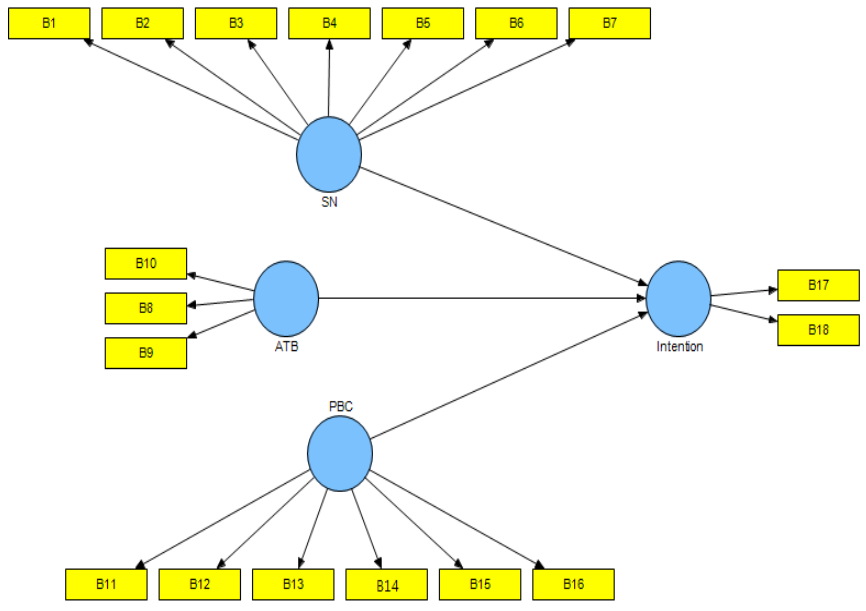

Gambar 3 Model penelitian

\section{Hasil dan Pembahasan}

Karakteristik responden meliputi jenis kelamin, jabatan, dan pendidikan terakhir. Dilihat dari jenis kelamin, mayoritas responden adalah laki-laki dengan persentase sebesar 54 persen, sedangkan responden berjenis kelamin perempuan sebesar 46 persen. Baik jurnalis tv laki-laki dan perempuan memiliki hak, kewajiban dan tanggung jawab yang sama dalam hal produksi pemberitaan di stasiun televisi. Masing-masing memiliki kesempatan yang sama untuk membuat dan menayangkan berita mengenai bank syariah di stasiun televisi tempat mereka bekerja. Lebih jelas mengenai karakteristik dapat dilihat pada Lampiran 2.

Pengetahuan bank syariah responden meliputi informasi tentang bank syariah, kunjungan ke bank syariah, kepemilikan bank syariah, dan penggunaan produk bank syariah ditampilkan pada Lampiran 3. Mayoritas responden telah mengetahui informasi mengenai bank syariah, yaitu dengan persentase sebesar 88 persen. Namun baru 40 persen responden yang memiliki rekening di bank syariah, sedangkan ada 49 persen pernah menggunakan produk bank syariah lainnya. Hal ini berarti jurnalis televisi sudah paham mengenai bank syariah termasuk keunggulan komparatif bank syariah dibandingkan dengan bank konvensional

\subsection{Pengujian Model Struktural (Inner Model)}

Model ini menggambarkan hubungan antarvariabel laten berdasarkan pada substantive theory. Menilai inner model dapat dilakukan dengan cara melihat model structural yang terdiri dari hubungan yang dihipotesiskan di antara konstruk-konstruk laten dalam model penelitian.

Melalui metode Bootstrapping pada SmartPLS, dapat diperoleh koefisien jalur (pathcoeffisients/S), dan nilai T-Statistik. Penulis dapat menilai signifikansi statistic model penelitian dengan menguji hipotesis untuk tiap jalur hubungan dengan teknik ini.

Niat jurnalis televisi berpengaruh terhadap variabel-variabel yang diukur dengan menggunakan pendekatan theory of planned behavior pada model gabungan sampai dengan pemilihan nyata. Hal tersebut mengindikasikan bahwa persepsi jurnalis televisi sangat baik dalam pembuatan berita bank syariah. Dalam model variabel-variabel yang mempunyai pengaruh yang signifikan ditunjukkan dengan syarat nilai $\mathrm{T}$ hitung $>\mathrm{T}$ tabel 
Amelia R, Hafidhuddin D, Tanjung H Faktor-Faktor yang Mempengaruhi Persepsi Jurnalis Televisi

$=1$,96. Lebih jelas nilai signifikansi jalur pada model gabungan dapat dilihat pada Tabel 2 dan Gambar 4.

Tabel 2 Hasil path coefficient model

\begin{tabular}{lccc}
\hline \multicolumn{1}{c}{ Jalur } & $\begin{array}{c}\text { Original Sample } \\
(\mathbf{O})\end{array}$ & $\begin{array}{c}\text { T Statistics } \\
(\mid \mathbf{O} / \text { STERR } \mid)\end{array}$ & $\begin{array}{c}\text { Hasil Uji } \\
\text { Hipotesis }\end{array}$ \\
\hline $\mathrm{SN} \rightarrow \mathrm{I}$ & 0,372450 & 3,4895 & Terima H1 \\
$\mathrm{ATB} \rightarrow$ & 0,015697 & 0,1346 & Tolak H2 \\
$\mathrm{I}$ & & 3,4716 & Terima H3 \\
$\mathrm{PBC} \rightarrow$ & 0,399735 & & \\
$\mathrm{I}$ & & &
\end{tabular}

(Data diolah, 2014)

Dari Tabel 2 dan Gambar 4, diketahui bahwa terdapat pengaruh positif dan signifikan di antara variabel-variabel yang ada dengan melihat nilainya pada tabel original sample (O) dan nilai siginifikansi pada $T$ Statistics.

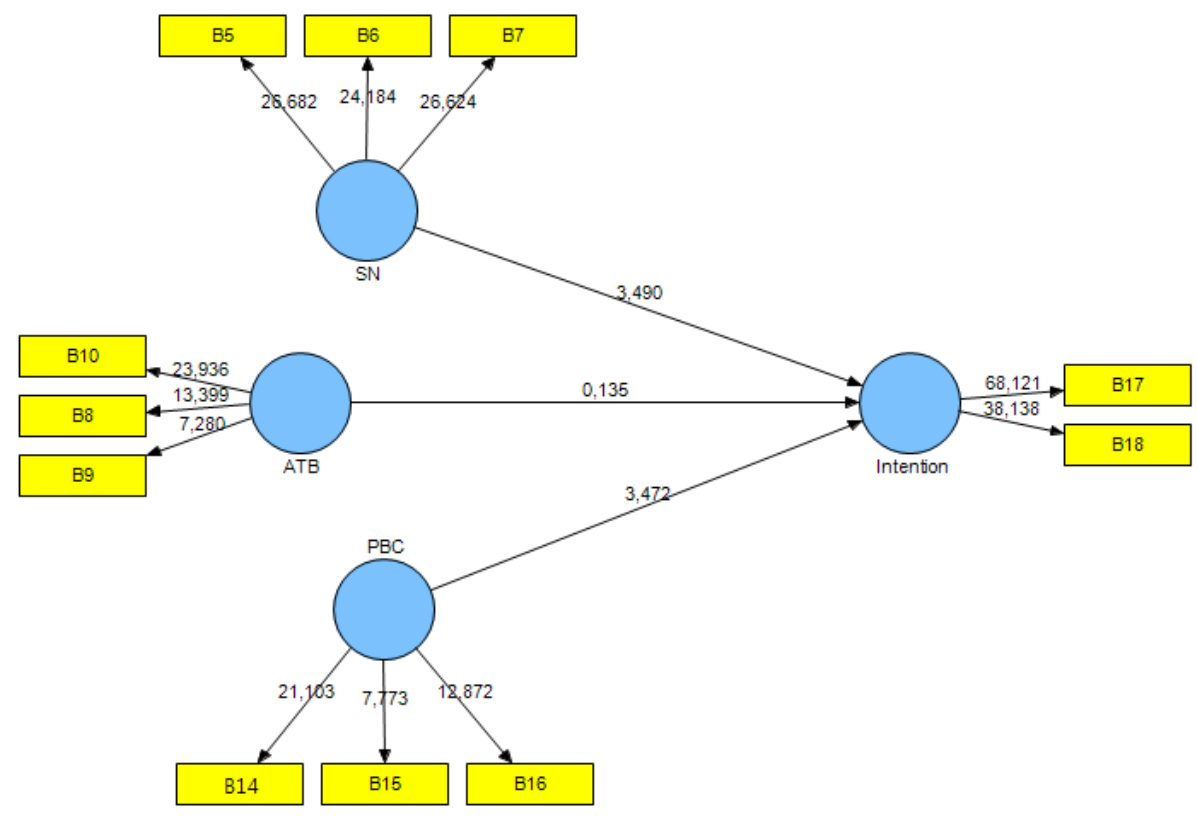

Gambar 4 Hasil perhitungan nilai t-hitung pada model

\subsubsection{Pengujian Hipotesis}

\section{Hipotesis $1\left(\mathbf{H}_{1}\right)$}

Pada model, variabel subjective norm (SN) memiliki pengaruh langsung terhadap Intention (I) sebesar 0,37 dengan nilai T Statistics sebesar 3,490 (lebih besar dari 1,96). $\mathrm{H}_{0}$ ditolak karena $T$ Statistics $>\mathrm{T}$ Tabel. Hal ini menunjukan bahwa $\mathrm{H}_{1}$ dalam penelitian diterima yaitu "subjective norm berpengaruh terhadap niat jurnalis televisi untuk membuat berita bank syariah".

\section{Hipotesis $2\left(\mathbf{H}_{2}\right)$}

Pada model, variabel Attitude Toward Behaviour (ATB) tidak memiliki pengaruh langsung terhadap merek Intention (I). Hal ini ditunjukan dengan nilai koefisien sebesar 
0,015 dengan nilai $T$ Statistics sebesar 0,135 (kurang dari 1,96). $\mathrm{H}_{0}$ diterima karena $T$ Statistics < T Tabel. Hal ini menunjukan bahwa $\mathrm{H}_{2}$ dalam penelitian ditolak yaitu "attitude toward behaviour tidak berpengaruh terhadap niat jurnalis televisi untuk membuat berita bank syariah".

\section{Hipotesis $3\left(\mathbf{H}_{3}\right)$}

Pada model, variabel Perceived Behavioural Control (PBC) memiliki pengaruh langsung terhadap merek Intention (I) sebesar 0,399 dengan nilai T Statistics sebesar 3,47 (lebih besar dari 1,96). $\mathrm{H}_{0}$ ditolak karena $T$ Statistics $>\mathrm{T}$ Tabel. Hal ini menunjukan bahwa $\mathrm{H}_{1}$ dalam penelitian diterima yaitu "perceived behavioural control berpengaruh terhadap niat jurnalis televisi untuk membuat berita bank syariah".

\subsubsection{Pengujian Model Pengukuran (Outer Model)}

Outer model menganalisis hubungan antara setiap blok indicator dengan variabel latennya (konstruk). Analisis dilakukan terhadap niat jurnalis televisi dengan pendekatan theory of planned behavior. Semua indicator pada model ini pada dasarnya bersifat reflektif, sehingga perlu dilakukan analisis outer model dengan menggunakan lima kriteria yaitu convergent validity, composite reliability, average variance extracted (AVE), akar kuadrat AVE, dan cross loading (Ghozali, 2008).

Model yang baik memiliki indikator dengan nilai loading factor yang lebih besar dari 0,7. Composite reliability menunjukkan konsistensi internal dengan standar nilai di atas 0,6. AVE menunjukkan validitas konstruk dengan standar nilai lebih besar dari 0,5, sedangkan AVE kuadrat dan cross loading menunjukkan validitas diskriminan di mana nilai standar untuk akar kuadrat AVE harus lebih besar dari nilai korelasi antar variabel, sedangkan cross loading setiap indikator harus memiliki loading lebih tinggi untuk setiap variabel laten yang diukur, dibandingkan dengan indikator untuk variabel laten lainnya. Hasil pengujian outer model terhadap kriteria-kriteria di atas dapat dilihat pada Tabel 3.

Tabel 3 Hasil penilaian kriteria dan standar nilai mode reflektif pada outer model

\begin{tabular}{|c|c|c|c|}
\hline No. & Kriteria & Standar & Hasil Penilaian \\
\hline 1. & $\begin{array}{l}\text { Loading Factor } \\
\text { (Convergent } \\
\text { Validity) }\end{array}$ & $\geq 0,7$ & $\begin{array}{l}\text { Seluruh indikator memiliki } \\
\text { nilai loading factor lebih dari } \\
0,7 \text { (Tabel 10) }\end{array}$ \\
\hline 2. & $\begin{array}{l}\text { Composite } \\
\text { Reliability }\end{array}$ & $>0,6$ & $\begin{array}{l}\mathrm{SN}=0,915 \\
\mathrm{ATB}=0,855 \\
\mathrm{PBC}=0,826 \\
\text { Intention }=0,954\end{array}$ \\
\hline 3. & Cronbach Alpha & $>0,7$ & $\begin{array}{l}\mathrm{SN}=0,861 \\
\mathrm{ATB}=0,746 \\
\mathrm{PBC}=0,698 \\
\text { Intention }=0,904\end{array}$ \\
\hline 4. & AVE & $>0,5$ & $\begin{array}{l}\mathrm{SN}=0,783 \\
\mathrm{ATB}=0,664 \\
\mathrm{PBC}=0,614 \\
\text { Intention }=0,912\end{array}$ \\
\hline 5. & $\begin{array}{l}\text { Akar Kuadrat } \\
\text { AVE }\end{array}$ & $\begin{array}{l}\text { Nilai akar kuadrat AVE, } \\
\text { lebih besar dari korelasi } \\
\text { variabel laten lainnya }\end{array}$ & $\begin{array}{l}\text { Lampiran } 4 . \text { Laten variable } \\
\text { correlation model gabungan }\end{array}$ \\
\hline 6 & $\begin{array}{l}\text { Cross Loading } \\
\text { (Discriminant }\end{array}$ & $\begin{array}{l}\text { Semua indikator } \\
\text { memiliki korelasi yang }\end{array}$ & $\begin{array}{l}\text { Lampiran 5. Cross Loading } \\
\text { model gabungan }\end{array}$ \\
\hline
\end{tabular}


Validity) lebih besar pada laten sendiri daripada korelasi

ke laten lainnya.

(Data diolah,2014)

Berdasarkan data pada Tabel 3, dapat diketahui bahwa dari ketiga model niat jurnalis televisi telah memenuhi syarat untuk menjadi model yang baik. Hal tersebut ditunjukan dengan nilai loading factor yang lebih besar dari standar yang telah ditetapkan. Menurut Chin dalam Ghozali (2008), jika koefisien atau loading factor dari masing-masing indikator pada model kurang dari 0,7 maka harus direduksi untuk menghasilkan model pengukuran yang baik. Proses reduksi dilakukan hingga seluruh indikator memiliki loading factor lebih dari 0,7.

Pada kriteria composite reliability, diketahui bahwa seluruh variabel laten yang digunakan dalam penelitian ini telah memiliki nilai lebih besar dari standar 0,6. Hal ini menunjukan bahwa semua variabel yang digunakan dalam penelitian mampu menjelaskan kondisi yang ingin diketahui melalui model niat jurnalis televisi secara konsisten. Pada kriteria cronbach alpha, diketahui bahwa hampir seluruh variabel mempunyai nilai cronbach alpha lebih besar dari 0,7 hanya variabel PBC yang kurang dari 0,7. Hal ini menunjukkan bahwa indikator masih dapat mengukur variabel (reliabel).

Pada kriteria AVE, dapat dilihat bahwa seluruh variabel laten memiliki nilai lebih dari 0,5 yang berarti variabel tersebut memenuhi syarat uji validitas konstruk. Pada kriteria akar kuadrat AVE, menunjukkan seluruh indikator memiliki nilai lebih besar dari korelasi variabel laten lainnya. Untuk kriteria terakhir yaitu cross loading juga menunjukkan bahwa semua indikator memiliki korelasi yang lebih besar pada laten sendiri daripada korelasi ke laten lainnya. Berdasarkan lima kriteria tersebut, maka dapat disimpulkan bawah model persepsi jurnalis televisi yang dibuat telah memenuhi syarat model yang baik, sehingga dapat dilanjutkan untuk dilakukan pengolahan untuk tahap berikutnya. Model awal dan akhir niat jurnalis televisi, dapat dilihat pada Gambar 5 dan Gambar 6. Berdasarkan Gambar 5 dan 6 diketahui bahwa terdapat beberapa indikator yang harus direduksi karena kurang memenuhi kriteria $(<0,7)$. Indikator-indikator yang direduksi dari ketiga model secara lengkap dapat dilihat pada Tabel 4.

Dari Tabel 4 terlihat bahwa indikator-indikator yang direduksi merupakan faktor-faktor yang dianggap tidak merefleksikan variabel latennya sehingga dianggap tidak valid untuk mengukur variabel tersebut.Pada model gabungan, indikator yang direduksi dari variabel SN adalah indikator B1, B2, B3, dan B4. Pada variabel PBC, indikator yang direduksi adalah B11, B12 dan B13. Untuk variabel ATB, tidak ada indikator yang direduksi.

Tabel 4 Indikator-indikator yang harus direduksi dari model

\begin{tabular}{|c|c|c|c|c|c|}
\hline \multicolumn{2}{|c|}{ Variabel SN } & \multicolumn{2}{|c|}{ Variabel ATB } & \multicolumn{2}{|c|}{ Variabel PBC } \\
\hline Indikator & $\begin{array}{l}\text { Loading } \\
\text { factor }\end{array}$ & Indikator & $\begin{array}{l}\text { Loading } \\
\text { factor }\end{array}$ & Indikator & $\begin{array}{l}\text { Loading } \\
\text { factor }\end{array}$ \\
\hline $\mathrm{B} 1 \rightarrow \mathrm{SN}$ & 0,657 & \multirow{4}{*}{\multicolumn{2}{|c|}{ Tidak ada yang direduksi }} & $\mathrm{B} 11 \rightarrow \mathrm{PBC}$ & $-0,339$ \\
\hline $\mathrm{B} 2 \rightarrow \mathrm{SN}$ & 0,589 & & & $\mathrm{~B} 12 \rightarrow \mathrm{PBC}$ & 0,066 \\
\hline $\mathrm{B} 3 \rightarrow \mathrm{SN}$ & 0,727 & & & $\mathrm{~B} 13 \rightarrow \mathrm{PBC}$ & $-0,024$ \\
\hline $\mathrm{B} 4 \rightarrow \mathrm{SN}$ & 0,656 & & & & \\
\hline
\end{tabular}

(Data diolah,2014) 


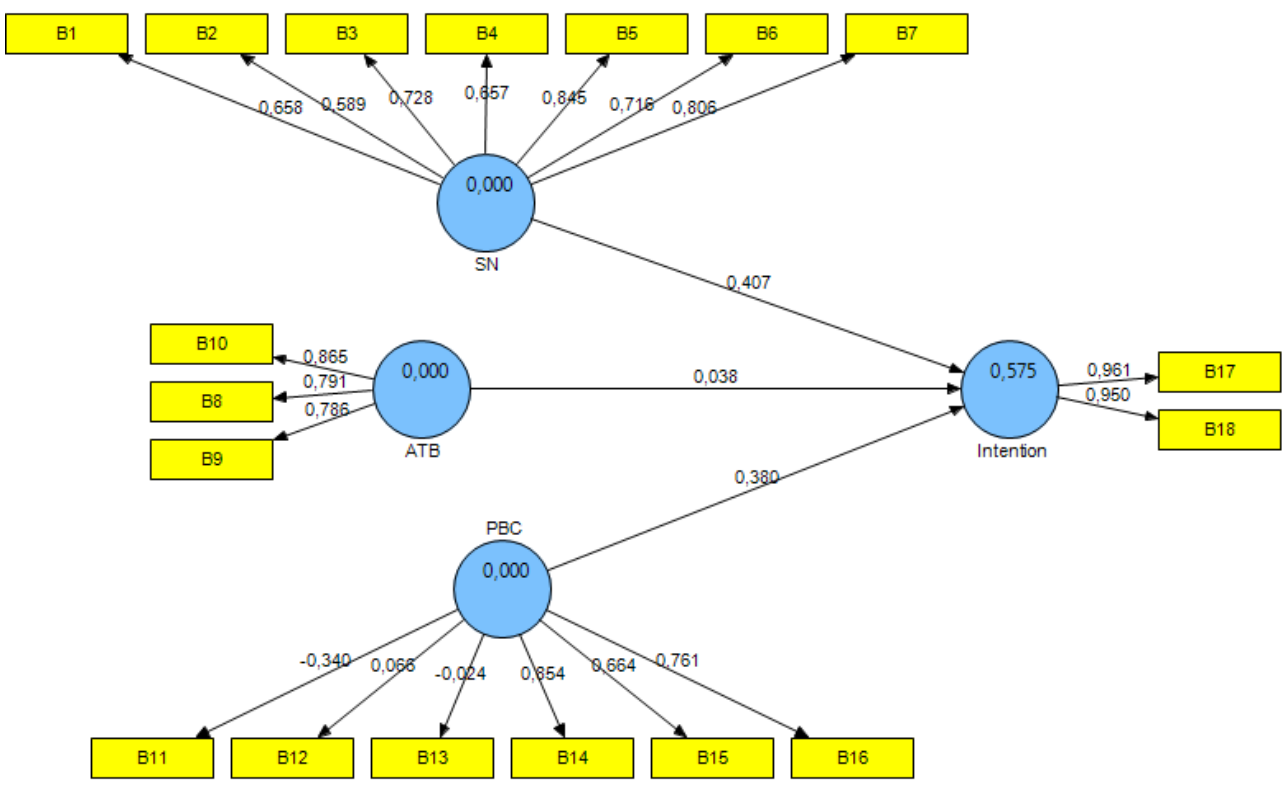

Gambar 5 Model awal niat jurnalis televisi



Gambar 6 Model akhir niat jurnalis televise

Nilai loading factor untuk semua indikator di atas 0,7 menunjukkan indikator-indikator yang merefleksikan variabel-variabel laten model niat jurnalis televisi dengan baik sehingga akan menghasilkan model yang tepat. Indikator-indikator yang memiliki nilai loading factor di atas 0,7 lebih jelasnya dapat dilihat pada Tabel 5. 
Amelia R, Hafidhuddin D, Tanjung H Faktor-Faktor yang Mempengaruhi Persepsi Jurnalis Televisi

Tabel 5 Indikator model niat jurnalis televisi dengan nilai loading factor yang memenuhi kriteria

\begin{tabular}{llllllll}
\hline \multicolumn{2}{l}{ Variabel SN } & \multicolumn{2}{c}{ Variabel ATB } & \multicolumn{2}{c}{ Variabel PBC } & \multicolumn{2}{c}{ Variabel Intention } \\
\hline Indikator & $\begin{array}{l}\text { Loading } \\
\text { factor }\end{array}$ & Indikator & $\begin{array}{l}\text { Loading } \\
\text { factor }\end{array}$ & Indikator & $\begin{array}{l}\text { Loading } \\
\text { factor }\end{array}$ & Indikator & $\begin{array}{l}\text { Loading } \\
\text { factor }\end{array}$ \\
\hline $\mathrm{B} 5 \rightarrow \mathrm{SN}$ & 0,915 & $\mathrm{~B} 8 \rightarrow \mathrm{SN}$ & 0,791 & $\mathrm{~B} 14 \rightarrow \mathrm{PBC}$ & 0,811 & $\mathrm{~B} 17 \rightarrow \mathrm{I}$ & 0,961 \\
$\mathrm{~B} 6 \rightarrow \mathrm{SN}$ & 0,863 & $\mathrm{~B} 9 \rightarrow \mathrm{SN}$ & 0,786 & $\mathrm{~B} 15 \rightarrow \mathrm{PBC}$ & 0,721 & $\mathrm{~B} 18 \rightarrow \mathrm{I}$ & 0,949 \\
$\mathrm{~B} 7 \rightarrow \mathrm{SN}$ & 0,875 & $\mathrm{~B} 10 \rightarrow \mathrm{SN}$ & 0,865 & $\mathrm{~B} 16 \rightarrow \mathrm{PBC}$ & 0,815 & & \\
\hline
\end{tabular}

(Data diolah, 2014)

Setiap variabel laten memiliki indikator utama yang memiliki loading factor terbesar, yaitu indikator yang paling merefleksikan variabel latennya. Hal ini berarti dari variabel laten yang memiliki nilai loading factor terbesar merupakan faktor yang dianggap paling penting oleh jurnalis televisi dalam membuat berita bank syariah. Tabel 6 menunjukkan kekuatan indikator merefleksikan variabel dalam model niat jurnalis televisi.

Tabel 6 Nilai loading factor tertinggi interelasi refleksi indikator

\begin{tabular}{lcc}
\hline \multirow{2}{*}{ Variabel Laten } & \multicolumn{2}{c}{ Hasil Perhitungan } \\
\cline { 2 - 3 } & Indikator & Loading Factor \\
\hline Subjective Norm (SN) & B5 & 0,915 \\
Attitude Toward Behaviour (ATB) & B10 & 0,865 \\
Perceived Behavioral Control (PBC) & B16 & 0,815 \\
Intention (I) & B17 & 0,961 \\
\hline
\end{tabular}

(Data diolah,2014)

Berdasarkan Tabel 6, dapat diketahui bahwa pada model gabungan indikator yang paling merefleksikan variabel SN adalah indikator B5, yaitu menyebarkan berita bank syariah menjadi salah satu cara menerapkan nilai-nilai Islam. Hal ini menunjukkan responden ingin selalu menerapkan nilai-nilai Islam dalam setiap pemberitaannya. Pada variabel ATB, indikator yang paling merefleksikan adalah indikator B10, yaitu berita bank syariah dapat menghindari riba, gharar, dan maysir. Hal ini menunjukan bahwa menghindari riba, gharar, dan maysir sangat penting. Pada variabel PBC, indikator yang paling merefleksikan adalah indikator B16, yaitu bank syariah sudah berkembang baik. Hal ini menunjukkan bahwa responden punya keyakinan atas perkembangan bank syariah di Indonesia. Pada variabel I, indikator yang paling merefleksikan adalah indicator B17, yaitu responden akan membuat berita bank syariah lebih banyak lagi. Hal ini menunjukan bahwa informasi bank syariah sangat penting untuk diberitakan.

\subsubsection{Hasil Koefisien Determinasi (R- square)}

Kekuatan untuk menjelaskan (explanatory power) yang dimiliki model, dapat dinilai dengan melihat $\mathrm{R}$-square $\left(\mathrm{R}^{2}\right)$ dari konstruk-konstruk endogen atau variabel dependen yakni variabel Intention. Nilai R-Square digunakan untuk menilai pengaruh variabel laten independen tertentu terhadap variabel laten dependen, apakah mempunyai pengaruh yang substantif. Tabel 7 menunjukkan R-Square untuk konstruk-konstruk dependen pada masing-masing model.

Tabel 7 Nilai $R$-square variabel laten model gabungan

\begin{tabular}{ccl}
\hline Variabel & R - Square & Penjelasan \\
\hline Intention $(\mathrm{I})$ & 0,514 & Moderat \\
\hline (data diolah, 2014) & &
\end{tabular}


Berdasarkan Tabel 7, hasil empiris dari pengujian model gabungan menunjukan bahwa variabel subjective norm (SN), attitude toward behaviour (ATB) dan perceived behavioural control (PBC) dapat menjelaskan variabel intention (I) sebesar 51,4\% sedangkan sisanya sebesar 48,6\% dijelaskan oleh variabel lain. Semakin besar nilai RSquare, maka semakin tepat juga prediksi penilaian pengaruh variabel SN, ATB, dan PBC terhadap variabel I. Hal ini mengindikasikan bahwa model tergolong moderat.

\section{Simpulan dan Saran}

\subsection{Simpulan}

Dari penelitian ini diketahui bahwa persepsi jurnalis televisi terhadap perkembangan bank syariah di Indonesia sangat baik. Hal ini terlihat pada variabel-variabel yang diukur dengan menggunakan pendekatan theory of planned behavior pada model gabungan sampai dengan pemilihan nyata.

Norma subjektif (SN) menunjukkan jurnalis televisi ingin selalu menerapkan nilai Islami dalam setiap pemberitaannya, untuk dapat menghindari riba, gharar, dan maysir (ATB), dimana jurnalis televisi yakin bank syariah di Indonesia sudah berkembang dengan baik (PBC), melalui pembuatan berita bank syariah lebih banyak lagi (I). Persepsi jurnalis televisi terhadap perkembangan bank syariah di Indonesia dipengaruhi oleh variabel norma subjektif (SN) dan persepsi kontrol keperilakuan (PBC).

\subsection{Saran}

Hasil penelitian ini berguna bagi praktisi bank syariah, Asosiasi Bank Syariah Indonesia (Asbisindo) untuk dapat menciptakan program sinaergi antara bank syariah dengan jurnalis televisi, baik secara bisnis maupun nonbisnis. Faktor norma subjektif (SN) dan persepsi kontrol keperilakuan (PBC) mempengaruhi persepsi jurnalis dalam memberitakan bank syariah. Hal ini memberi implikasi manajerial bahwa bank syariah sebaiknya mengetahui variabel yang dianggap penting menurut jurnalis televisi agar dapat membentuk persepsi positif jurnalis terhadap pemberitaan bank syariah yang akan berkontribusi terhadap perkembangan bank syariah di Indonesia.

Intensitas terhadap program acara mengenai berita atau informasi bank syariah harus ditayangkan secara rutin, bukan hanya di waktu-waktu tertentu, seperti di bulan Ramadan. Program acara tersebut juga harus didukung oleh jurnalis televisi yang mampu mengolah berita bank syariah agar menarik dan informatif. Hal ini bertujuan agar informasi bank syariah dapat diterima dengan baik oleh pemirsa.

Penelitian selanjutnya perlu dilakukan kajian lebih lanjut mengenai persepsi pemirsa yang menyaksikan berita bank syariah di media televisi dengan jumlah responden yang lebih besar.

\section{Daftar Pustaka}

Al Quran dan Terjemahannya. 2000. Mujamma’ Al Malik Fahd Li Thiba'at Al Mush-haf. Asy-Syarif Medinah Munawwarah (Arab Saudi)

Ajzen Icek. 1991. The Theory of Planned Behavior. Organizational Behavior and Human Decision Processes. Volume 50: 179-211. Journal of Psychology, University of Massachussetts (US). 
Amelia R, Hafidhuddin D, Tanjung H Faktor-Faktor yang Mempengaruhi Persepsi Jurnalis Televisi

Berry David. 2008. Journalism, Ethics, and Society [ebook]. Surrey (UK): Ashgate Publishing Limited.

Badan Pusat Statistik. 2012. Proporsi Penduduk Berumur 10 Tahun ke Atas yang Menonton Acara Televisi Selama Seminggu Terakhir menurut Provinsi, tipe Daerah dan Jenis Kelamin. http://bps.go.id/tab_sub/view.php?kat=1\&tabel=1\&daftar=1\&id_subyek= 27\&notab=2. (2 September 2014).

Bank Indonesia. 2014. Nih, Tantangan Perbankan Syariah Menurut BI. http://www.infobanknews.com/2013/12/nih-tantangan-perbankan-syariah-menurutbi/. (11 Desember 2014).

Bray Jeff. Consumer Behaviour Theory: Approaches and Models [ebook]. 2008. United Kingdom (UK): Bournemouth University.

CIA. 2013. The World Fact Book. https://www.cia.gov/library/publications/the-worldfactbook/fields/2122.html\#bx. (14 Januari 2014)

Content and Knowledge Management (CKM) Metro TV. 2014. Data Rating dan Share Televisi Swasta (tidak dipublikasi). Jakarta (ID).

Ghozali I. 2005. Structural Equation Modelling Teori, Konsep, dan Aplikasi dengan Program Lisrel 8.45. Semarang (ID): Universitas Diponegoro.

Ghozali I. 2008. Structural Equation Modelling Metode Alternatif dengan Partial Least Square. Edisi 2. Semarang (ID): Universitas Diponegoro.

Hanitzch et al (2010). Modeling Perceived Influences on Journalism: Evidence From A Cross-National Survey of Journalists. Journalism and Mass Communication Quarterly. Vol. 87No. 1: 5-22. www.proquest.com (16 September 2014).

Ikatan Jurnalis Televisi Indonesia (IJTI). Anggaran Dasar. http://www.ijti.org/Download.php. (20 Agustus 2014 ).

Ikatan Jurnalis Televisi Indonesia (IJTI). Kode Etik Ikatan Jurnalis Televisi Indonesia. http://aji.or.id/read/kode-etik.html. (diunduh 20 Agustus 2014).

Irviana RR Kathrin. 2008. Analisis Segmen Pasar dan Perilaku Nasabah terhadap Bank Syariah di Wilayah DKI Jakarta [tesis]. Program Studi Manajemen dan Bisnis Sekolah Pascasarjana Institut Pertanian Bogor (ID).

Komisi Pemilihan Umum. 2014. Penetapan Rekapitulasi Hasil Penghitungan Perolehan Suara dan Hasil Pemilihan Umum Presiden dan Wakil Presiden Tahun 2014. http://www.kpu.go.id/index.php/ pages/detail/2014/316. (diunduh pada 5 Maret 2015).

Kotler P, Kevin LK. 2009. Manajemen Pemasaran. Ed ke-13. Jilid I. Terjemahan dari: Bob Sabran. Jakarta (ID): Penerbit Erlangga.

Perse Elizabeth M. 2001. Media Effects and Society [ebook]. Lawrence Erlbaum Associates Publishers. London (UK).

Schiffman LG, Kanuk LL. 2010, Consumer Behaviour. Ed ke-10. New Jersey (US): Prentice Hall

Sumarwan Ujang. 2011. Perilaku Konsumen. Bogor (ID): Penerbit Ghalia Indonesia.

Tanjung Hendri, Abrista Devi. 2013. Metode Penelitian Ekonomi Islam. Bekasi (ID): Gramata Publishing.

Tsfati, Yariv dan Oren Livio. 2008. Exploring Journalists' Perceptions of Media Impact. Journalism and Mass Communication Quarterly. Vol. 85 No. 1: 113-130. www.proquest.com (16 September 2014)

Warmanto, WB, Handhika NT. 2007. Analisa Hubungan Keperilakuan yang Dirasakan terhadap Perilaku Berbagi Pengetahuan Manajer. Studi Empiris pada Perusahaan di Wilayah Jakarta [tesis]. Universitas Multimedia Nusantara, Tangerang (ID). 


\section{Lampiran 1 Indikator Pengukuran}

\begin{tabular}{|c|c|c|c|}
\hline No & Variabel & Indikator & Skala \\
\hline & & 1. Pengaruh keluarga & Likert \\
\hline \multirow[t]{2}{*}{1} & Norma Subyektif & 2. Pengaruh non keluarga & Likert \\
\hline & & 3. Mengikuti pengaruh keluarga & Likert \\
\hline 2 & Motivasi Mematuhi & 4. Mengikuti pengaruh non keluarga & Likert \\
\hline \multirow[t]{4}{*}{3} & Kepercayaan & $\begin{array}{l}\text { 5. Berita bank syariah merupakan salah satu cara } \\
\text { menerapkan nilai Islam }\end{array}$ & Likert \\
\hline & Terhadap Perilaku & $\begin{array}{l}\text { 6. Berita bank syariah dapat memberi informasi } \\
\text { untuk masyarakat }\end{array}$ & Likert \\
\hline & & $\begin{array}{l}\text { 7. Berita bank syariah dapat menghindari riba, } \\
\text { gharar \&maysir }\end{array}$ & Likert \\
\hline & & 8. Penting menerapkan nilai Islam di kehidupan & Likert \\
\hline \multirow[t]{4}{*}{4} & Evaluasi Keluaran & $\begin{array}{l}\text { 9. Penting untuk memberi informasi ke } \\
\text { masyarakat }\end{array}$ & Likert \\
\hline & & 10. Penting menghindari riba, gharar \&maysir & Likert \\
\hline & & 11. Bank syariah belum menjadi kebutuhan saya & Likert \\
\hline & & 12. Informasi bank syariah sulit didapat & Likert \\
\hline \multirow[t]{2}{*}{5} & $\begin{array}{c}\text { Kontrol } \\
\text { Kenerilakuan }\end{array}$ & 13. Bank syariah belum berkembang dengan baik & Likert \\
\hline & & $\begin{array}{l}\text { 14. Bank syariah merupakan kebutuhan saya } \\
\text { sebagai muslim }\end{array}$ & Likert \\
\hline \multirow[t]{2}{*}{6} & Kekuatan Faktor & 15. Informasi bank syariah mudah didapat & Likert \\
\hline & Kontrol & ariah sudah berkembang dengan baik & Likert \\
\hline \multirow[t]{2}{*}{7} & Niat & 17. Membuat berita bank syariah lebih banyak & Likert \\
\hline & & $\begin{array}{l}\text { 18. Membuat berita ekonomi syariah lebih } \\
\text { banyak lagi }\end{array}$ & Likert \\
\hline
\end{tabular}

Lampiran 2 Karakteristik responden

\begin{tabular}{|c|c|}
\hline Karakteristik & Persentase \\
\hline \multicolumn{2}{|c|}{ Jenis Kelamin } \\
\hline Laki-laki & 54 \\
\hline Perempuan & 46 \\
\hline \multicolumn{2}{|c|}{ Jabatan } \\
\hline Reporter & 21 \\
\hline Juru kamera & 8 \\
\hline Jurnalis video & 6 \\
\hline Junior/associate producer & 21 \\
\hline Produser & 27 \\
\hline Produser eksekutif & 5 \\
\hline Lainnya & 12 \\
\hline \multicolumn{2}{|c|}{ Pendidikan Terakhir } \\
\hline Diploma & 8 \\
\hline S1 & 81 \\
\hline S2 & 11 \\
\hline
\end{tabular}


Lampiran 3 Pengetahuan Bank Syariah

\begin{tabular}{lcc}
\hline & Pertanyaan & Persentase \\
\hline \multicolumn{2}{c}{ Pengetahuan informasi tentang bank syariah } \\
Ya & 88 \\
Tidak & 12 \\
& Pernah berkunjung ke bank syariah & 71 \\
Ya & & 29 \\
Tidak & & \\
& Punya rekening di bank syariah & \\
Ya & & 40 \\
Tidak & 60 \\
& Pernah gunakan produk bank syariah \\
Ya & 49 \\
Tidak & 51 \\
\hline
\end{tabular}

(Data diolah,2014)

Lampiran 4 Output hasil pengolahan PLS model niat jurnalis televisi dengan pendekatan CDM model gabungan

\begin{tabular}{ccllll} 
Latent variable correlations dan akar AVE Model Gabun \\
\cline { 2 - 6 } Variabel Laten & ATB & Intention & PBC & SN \\
\hline ATB & $\mathbf{0 , 8 1 4}$ & & & \\
Intention & 0,541 & $\mathbf{0 , 9 5 4}$ & & \\
PBC & 0,639 & 0,659 & $\mathbf{0 , 7 8 3}$ & \\
SN & 0,725 & 0,651 & 0,669 & $\mathbf{0 , 8 8 4}$ \\
\hline \multicolumn{6}{c}{ (Data diolah,2014) }
\end{tabular}

Lampiran 5 Hasil Crossloading Model

\begin{tabular}{clccc}
\hline & ATB & PBC & SN & Intention \\
\hline B5 & 0,662593 & 0,630350 & $\mathbf{0 , 9 1 5 3 1 8}$ & 0,579578 \\
B6 & 0,645047 & 0,531337 & $\mathbf{0 , 8 6 3 5 6 7}$ & 0,588315 \\
B7 & 0,615917 & 0,616411 & $\mathbf{0 , 8 7 5 3 2 7}$ & 0,560234 \\
B8 & $\mathbf{0 , 7 9 1 0 3 1}$ & 0,546130 & 0,508689 & 0,409436 \\
B9 & $\mathbf{0 , 7 8 6 3 3 7}$ & 0,417514 & 0,598604 & 0,416657 \\
B10 & $\mathbf{0 , 8 6 5 2 4 4}$ & 0,591429 & 0,657259 & 0,491480 \\
B14 & 0,655596 & $\mathbf{0 , 8 1 1 6 3 6}$ & 0,730364 & 0,631901 \\
B15 & 0,372981 & $\mathbf{0 , 7 2 1 9 5 5}$ & 0,292796 & 0,364847 \\
B16 & 0,411863 & $\mathbf{0 , 8 1 5 4 5 2}$ & 0,447232 & 0,495390 \\
B17 & 0,554771 & 0,649942 & 0,678622 & $\mathbf{0 , 9 6 1 2 8 2}$ \\
B18 & 0,474759 & 0,607150 & 0,558848 & $\mathbf{0 , 9 4 9 6 1 2}$ \\
\hline \multicolumn{5}{c}{ Data diolah, 2014) }
\end{tabular}

